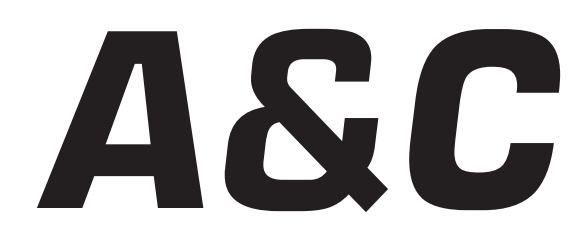

Revista de Direito Administrativo \& Constitucional

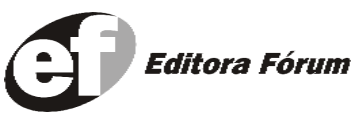

A\&C R. de Dir. Administrativo e Constitucional, Belo Horizonte, ano 6, n. 23, p. 1-253, jan./mar. 2006 


\section{A\&C REVISTA DE DIREITO ADMINISTRATIVO E CONSTITUCIONAL}

\section{IPDA}

Instituto Paranaense

de Direito Administrativo

Direção Geral

Romeu Felipe Bacellar Filho

Direção Editorial

Paulo Roberto Ferreira Motta

Direção Executiva

Emerson Gabardo

Conselho de Redação

Edgar Chiuratto Guimarães

Adriana da Costa Ricardo Schier

Célio Heitor Guimarães

Conselho Editorial

Adilson Abreu Dallari

Alice Gonzáles Borges

Carlos Ari Sundfeld

Carlos Ayres Britto

Carlos Delpiazzo

Cármen Lúcia Antunes Rocha

Celso Antônio Bandeira de Mello

Clèmerson Merlin Clève

Clóvis Beznos

Enrique Silva Cimma

Eros Roberto Grau

Fabrício Motta

Guilhermo Andrés Muñoz (in memoriam)

Jaime Rodríguez-Arana Muñoz

Jorge Luís Salomoni
José Carlos Abraão
José Eduardo Martins Cardoso

José Luís Said

José Mario Serrate Paz

Juan Pablo Cajarville Peruffo

Juarez Freitas

Julio Rodolfo Comadira

Luís Enrique Chase Plate

Lúcia Valle Figueiredo

Manoel de Oliveira Franco Sobrinho

(in memoriam)

Marçal Justen Filho

Marcelo Figueiredo

Márcio Cammarosano

Maria Cristina Cesar de Oliveira
Nelson Figueiredo

Odilon Borges Junior

Pascual Caiella

Paulo Eduardo Garrido Modesto

Paulo Henrique Blasi

Paulo Neves de Carvalho (in memoriam)

Paulo Ricardo Schier

Pedro Paulo de Almeida Dutra

Regina Maria Macedo Nery Ferrari

Rogério Gesta Leal

Rolando Pantoja Bauzá

Sérgio Ferraz

Valmir Pontes Filho

Yara Stropa

Weida Zancaner

\footnotetext{
A246 A\&C Revista de Direito Administrativo e Constitucional. ano 3, n. 11, jan./mar. 2003. Belo Horizonte: Fórum, 2003.

Trimestral

ano 1, n.1, 1999 até ano 2, n.10, 2002 publicada pela Editora Juruá em Curitiba

ISSN: 1516-3210

1. Direito Administrativo. 2. Direito Constitucional. I. Fórum.
}

CDD: 342 CDU: 33.342

(c) Editora Fórum Ltda. 2006

Todos os direitos reservados. É proibida a reprodução total ou parcial, de qualquer forma ou por qualquer meio eletrônico ou mecânico, inclusive através de processos xerográficos, de fotocópias ou de gravação, sem permissão por escrito do possuidor dos direitos de cópias (Lei $n^{\circ}$ 9.610, de 19.02.1998).

Editora Fórum Ltda

Av. Afonso Pena, 2770 - 15\%16ªndar - Funcionários

CEP 30130-007 - Belo Horizonte/MG - Brasil

Tel.: 08007043737

Internet: www.editoraforum.com.br

e-mail: editoraforum@editoraforum.com.br
Editor responsável: Luís Cláudio Rodrigues Ferreira Projeto gráfico e diagramação: Luis Alberto Pimenta Revisora: Olga M. A. Sousa

Pesquisa jurídica: Fátima Ribeiro - OAB/MG 74868

Bibliotecária: Nilcéia Lage de Medeiros

CRB 1545/MG 6a região

Os conceitos e opiniões expressas nos trabalhos assinados são de responsabilidade exclusiva de seus autores.

Impressa no Brasil / Printed in Brazil

Distribuída em todo Território Nacional 


\title{
O Conselho Nacional de Justiça e a administração do Poder Judiciário*
}

Carlos Eduardo Thompson Flores Lenz

Desembargador Federal do TRF/4a Região

\begin{abstract}
“Je n'ai pas besoin de faire remarquer l'utilité d'une bonne et exacte justice au point de vue du gouvernement, et de répéter qu'elle est une des premières conditions de la stabilité des États. C'est une vérité devenue banale et qui n'a plus besoin de démonstration. Il est certain qu'une mauvaise distribution de la justiça affaiblit les forces d'un empire et prépare sa décadence".

BORDEAUX, Raymond. Mémoire sur la Réformation de la Justice. Évreux: Imprimerie de Auguste Hérissey, 1857, p. 184.
\end{abstract}

Sumário: 1 Introdução - 2 A função disciplinar e os órgãos do Poder Judiciário - 3 A criação do Conselho Nacional de Justiça - Antecedentes históricos 4 Órgãos congêneres do Direito comparado - 5 Considerações finais

Palavras-chave: Brasil. Conselho Nacional de Justiça (CNJ) ; Poder Judiciário, Brasil ; Poder Judiciário, administração ; Poder Judiciário, órgãos ; Poder Judiciário, função disciplinar

\section{Introdução}

Passados cinco anos, retorno a esta Casa de altos estudos para novamente ter a honra de lhe ocupar a tribuna, atendendo à convocação do seu ilustre Presidente, Professor Aldo Leão Ferreira, com o encargo de versar aspectos relevantes da Reforma do Poder Judiciário, em especial, o novel Conselho Nacional de Justiça.

Foi-me sumamente honroso o convite a mim dirigido pelo prestigiado Instituto dos Advogados do Rio Grande do Sul, por meio de seu eminente Presidente, e procurarei cumpri-lo com a exação que recomendam a elevação, a seriedade e a reputação deste Sodalício.

A reforma do Poder Judiciário, seria um truísmo dizê-lo, há muito tem sido reclamada, seja dentro de seus próprios quadros, os magistrados, seja fora deles.

As sucessivas tentativas de aperfeiçoamento das instituições judiciá-

* Conferência proferida no Instituto dos Advogados do Rio Grande do Sul em 27.10.2005.

A \& C R. de Dir. Administrativo e Constitucional, Belo Horizonte, ano 6, n. 23, p. 21-37, jan./mar. 2006 
rias esbarraram em dificuldades de toda sorte, o que acaba minando a sua efetiva conclusão, deixando a sensação de obra inacabada.

Nesse sentido, o recente "Rapport de la Commission de Réflexion sur la Justice", elaborado por uma Comissão de Juristas da França, designada pelo Presidente da República, e que teve por Presidente Pierre Truche, primeiro Presidente da Corte de Cassação, verbis:

Dans sa démarche, la commission a naturellement été confrontée aux obstacles traditionnels à tout réforme.

L'obstacle des tabous, d'abord: que de réformes jugées bonnes en leur principe ne voient pas le jour parce que l'opinion publique n'y serait pas prête ou parce qu'il serait porté atteinte à une tradition respectable! De tels tabous sont fréquents en matière de justice. Or, si une évolution voire une rupture avec une tradition dépassée sont nécessaires, elles doivent pouvoir être expliquées et comprises.

Le risque de l'impatience, ensuite: vouloir apporter à des problèmes complexes une réponse rapide peut conduire à demeurer à la surface des choses, donc à seulement réagir. Agir, au contraire, suppose un plan dont l'exécution peut demander plusieurs années. Lessentiel est alors de fixer les perspectives et les étapes et surtout de s'y tenir.

Enfin et surtout, l'obstacle des moyens. Toute réforme a un coût. La tentation peut être grande, en période de rigueur budgétaire, de limiter la réflexion à une meilleure utilisation des moyens actuels. Cette hypothèque a été levée par le Président de la République qui, en installant la commission, a précisé qu'accroître les moyens est une nécessité pour mettre en place une justice de qualité. Nous aurons l'occasion d'évoquer à plusiers reprises ce problème: l'évoquer, et non l'invoquer comme un obstacle à toute réforme en profondeur. ${ }^{1}$

Reforma pronta e ampla, precedida de minucioso estudo, eis a grande tarefa que reclama a conjugação de esforços de todos os responsáveis por esse importante serviço público eminentemente nacional, como o dizia João Mendes Jr.

A Emenda Constitucional $n^{\circ} 45 / 04$ tem sua origem em movimento iniciado nos anos noventa, a fim de promover a reestruturação da magistratura, com profunda reforma de sua base, visando a corrigir os defeitos existentes nas normas que a disciplinam e a torná-la mais eficiente.

Que tal desiderato não restou alcançado é de todos sabido, tanto que acerbas críticas receberam os seus dispositivos.

Com efeito, além de omissa em relação a questões e problemas que deveriam ter sido enfrentados, a Emenda Constitucional $n^{\circ} 45$ contém dispositivos nocivos e desastrados como, por exemplo, o fim das férias ${ }^{1}$ Rapport de la Commission de Réflexion sur la Justice. Paris: La Documentation Française, 1997, p. 8. 
coletivas nos tribunais de segundo grau e a mutilação da competência do Supremo Tribunal Federal ao transferir para o Superior Tribunal de Justiça a competência para julgar a homologação de sentenças estrangeiras e a concessão de exequatur às cartas rogatórias, medida injustificada e que em nada contribuirá para o alívio do excesso de serviço da nossa Suprema Corte.

Entretanto, de par com isso, inovações de alto valor a aludida Emenda Constitucional introduziu na Carta Magna, como a criação de um novo órgão do Poder Judiciário: O Conselho Nacional de Justiça.

\section{A função disciplinar e os órgãos do Poder Judiciário}

No Brasil, os juízes, no exercício da função jurisdicional, e mesmo como decorrência da independência que a Constituição lhes assegura, encontram-se livres de quaisquer vínculos hierárquicos.

Todavia, prevê a Lei Orgânica da Magistratura uma jurisdição censória exercida pela corregedoria dos tribunais com a finalidade de zelar pela disciplina dos juízes. Consoante leciona João Mendes Jr., "a ação disciplinar é criada especialmente no interesse da própria magistratura. Ela, só ela, deve, tanto quanto for possível, ter a iniciativa de corrigir os desvios de seus membros, desde que se trata de faltas que não são crimes nem erros de ofício; pois, em relação ao sentimento de justiça para com as partes, nem sempre o juiz indiscreto ou menos circunspecto é o menos justo: tão cheia de contrastes é a natureza humana. Entretanto, a indiscrição e a falta de circunspeção concorrem para habituar à negligência, à indolência e, quase sempre, produzem a injustiça, se não imediatamente, pelo menos indiretamente. Seja como for, a circunspeção é uma das partes integrantes da prudência”. ${ }^{2}$

Cabe à Lei Orgânica da Magistratura conceituar, fixar e estabelecer as sanções disciplinares dos magistrados, as suas linhas mestras, remanescendo o seu procedimento, em caráter supletivo, aos regimentos internos dos tribunais.

Ademais, deve-se ter presente que, em se tratando de membros do Poder Judiciário, a noção de falta disciplinar é mais ampla que a violação de obrigação especificamente profissional, visto que aos juízes exigem-se predicados outros que aos servidores em geral, como agente político que é, nos termos da Constituição, exercendo parcela vital de poder como emanação da soberania nacional.

2 Plano de Reforma Judiciária. São Paulo: Siqueira, Nagel \& Comp., 1912, p. 170,

A \& C R. de Dir. Administrativo e Constitucional, Belo Horizonte, ano 6, n. 23, p. 21-37, jan./mar. 2006 
Ora, a jurisdição é uma das funções que o Estado exerce, como entidade soberana, dentro de seu território.

Mas, se aos juízes a Constituição confere garantias, prerrogativas e vantagens diferenciadas, também é inegável que a eles, mais que aos funcionários públicos em geral, se deve exigir o correto cumprimento de seus deveres funcionais.

Nesse passo, acertado o ensinamento de René Japiot, verbis:

La vie publique et privée des juges est soumise à des conditions d'honorabilité, de respect de soi-même, plus étroites que celles qui incombent à tout citoyen. Non seulement les magistrats doivent s'abstenir de tout acte immoral ou illicite, mais encore d'actes licites en eux-mêmes, pour mettre leur considération à l'abri de tout soupçon et sauvegarder l'honneur du corps auquel ils appartiennent. ${ }^{3}$

Nesse sentido, ainda, o pensamento do saudoso Ministro Orosimbo Nonato, expresso em seu discurso proferido em 1957, ao ser agraciado com a Medalha de Honra ao Mérito, oportunidade em que discorreu acerca dos elevados atributos morais e intelectuais exigidos dos juízes, verbis:

O exercício de missão tão espinhada de dificuldades, sempre que nobilitado pela isenção e dignidade, deve levar os censores à indulgência quando se trate de erros de inteligência supostos ou reais, guardando-se eles de esvaziarem o seu carcás de contumélias sempre que seja uma sentença reformada ou esta lhes pareça improcedente.

A esse apelo, entretanto, de maior acatamento ao juiz, outro deve ser enumerado para que não deixe o magistrado, nunca por nunca, como fiéis companheiras de seu sacerdócio, a modéstia, a sisudez, a discrição, a serenidade. Ao juiz não lhe bastará a posse das altas virtudes da probidade, do desinteresse, do saber, da coragem, da altivez e da independência.

Ainda se lhe exige que elas se exerçam em medida áurea, em supremo equilíbrio, temperadas na discrição, no amor, na penumbra, na aversão aos arruídos da publicidade e das deselegâncias do exibicionismo.

Quem se dedica à sacratíssima das missões exercíveis no século — para lembrar conceito de Rui Barbosa — vota-se à modéstia e ao quase obscurecimento. ${ }^{4}$

Dentre os deveres que incumbe ao juiz, qualquer que seja o grau de sua jurisdição, figura o do pontual desempenho do ofício.

A propósito, dispõe o art. $5^{\circ}$, LXXVIII, da Constituição, na redação da Emenda Constitucional $n^{\circ} 45 / 04$, que a todos os cidadãos, no âmbito

\footnotetext{
3 JAPIOT, René. Traité Élémentaire de Procédure Civile et Commerciale. 3. ed. Paris: Libr. Arthur Rousseau, 1935, p. 187, n. 223.

4 Apud MÓSCA, Hugo. Orosimbo Nonato - Apóstolo do Direito. Brasília: Thesaurus, 1991, p. 18.
} 
judicial e administrativo, são assegurados a razoável duração do processo e os meios que garantam a celeridade de sua tramitação.

Realmente, aos juízes não é permitido comportamento, no exercício de suas funções ou fora delas, que destoe da mais perfeita correção.

\section{A criação do Conselho Nacional de Justiça - Antecedentes históricos}

A Emenda Constitucional no 45/04 criou o Conselho Nacional de Justiça, incluindo-o como órgão do Poder Judiciário, abaixo do Supremo Tribunal Federal, o que fez no art. 92, I - A. Logo adiante, no art. 103 - B, fixou a composição desse órgão, bem como as suas atribuições.

O Conselho Nacional de Justiça tem a sua sede na Capital da República e jurisdição em todo o território nacional. E será integrado por 15 membros, dos quais nove serão magistrados e seis não integrantes da magistratura.

A propósito da composição e da competência do Conselho Nacional de Justiça, anota o ilustre Desembargador Federal Vladimir Passos de Freitas, ex-Presidente do TRF $/ 4^{\mathrm{a}}$ Região, verbis:

O CNJ do Brasil foi incluído como órgão do Poder Judiciário (art. 92, I-A). Sob seu controle estarão todos os ramos do Poder Judiciário. Ele terá tamanho e composição diferentes do mexicano e do argentino (art. 103-B). Serão 15 Conselheiros, dos quais 9 juízes de instâncias e ramos diversos do Judiciário e 6 de origem externa ( 2 do Ministério Público, 2 advogados e 2 cidadãos indicados pelo Congresso). O número de 15 Conselheiros não será pequeno a ponto de tornar o $\mathrm{CNJ}$ inoperante, nem grande demais de modo a deixá-lo lento e burocrático.

Caberá ao CNJ conduzir a política nacional do Judiciário, tocando-lhe o controle da atuação administrativa e financeira do referido Poder (art. 103, §4 ${ }^{\circ}$, caput e inc. VII). Até a reforma, o Judiciário se manifestava através de 95 Tribunais, sendo 5 Superiores, 5 Federais, 24 do Trabalho, 27 Eleitorais e 34 Estaduais (27 TJs, 4 Alçadas e 3 Militares). Alie-se a isso várias associações de magistrados, nacionais e locais. O discurso e os objetivos muitas vezes eram conflitantes. Parece, assim, oportuno definir uma linha de política uniforme.

Compete ao $\mathrm{CNJ}$, originariamente ou de forma supletiva, o controle disciplinar dos magistrados (art. 103, $4^{\circ}$, incs. III e VI). De todas as atribuições do novo órgão esta, certamente, é a mais complexa. O Conselho Nacional terá competência para receber e conhecer das reclamações contra membros ou órgãos do Poder Judiciário, inclusive contra os prestadores de serviços notariais e de registro (art. 103, $b, \S 4^{\circ}$, inc. III). O dispositivo é preocupante. Atuam no Brasil cerca de 12.000 juízes e um número enorme - e desconhecido - de funcionários do foro judicial e do extra-judicial. O gigantismo do Judiciário brasileiro vai gerar um grande número de representações. Se não for criada uma estrutura moderna e eficiente, o CNJ corre o risco de cair no descrédito. 
Ao CNJ atribui-se a função incomum de rever de ofício ou mediante provocação, os processos disciplinares de juízes e membros de tribunais julgados há menos de um ano (art. 103, $b, \S 4^{\circ}$, inc. V). Absolutória ou condenatória, a decisão administrativa poderá ser revista. O dispositivo revela desconfiança com o atual sistema de apuração de faltas administrativas pelos Tribunais. ${ }^{5}$

O Conselho Nacional de Justiça terá um Corregedor, que será o Ministro do Superior Tribunal de Justiça, nos termos do disposto no art. 103 - B, $\S 5^{\circ}$, II e III, da $\mathrm{CF} / 88$, a quem compete receber as declarações e denúncias formuladas por qualquer interessado, relativos aos juízes e aos serviços judiciários, competindo-lhe, ainda, exercer as funções de inspeção e correição geral, podendo, para tanto, requisitar e designar magistrados, delegando-lhes atribuições, bem como requisitar servidores de juízos ou tribunais, na forma prevista no texto constitucional.

Por conseguinte, todos os magistrados, inclusive dos tribunais superiores da justiça ordinária ou especial, ficam sob a jurisdição censória do Conselho Nacional de Justiça.

Será ele, portanto, um órgão de grande destaque nos quadros da magistratura nacional, pelas relevantes funções censórias que a Carta Magna lhe confere, bem como por incumbir a ele supervisionar a administração superior do Judiciário, mediante a investigação e o exame dos casos de emperramento da máquina judiciária, formulando propostas e sugestões para o melhor funcionamento da justiça, tornando-a efetiva e pronta, como agora o quer a Constituição, em seu art. $5^{\circ}$, LXXVIII.

Ao Supremo Tribunal Federal, na forma do disposto no art. 102, I, "r", da CF/88, compete o controle jurisdicional das decisões do Conselho Nacional de Justiça, notadamente em matéria disciplinar, no caso de se verificar ilegalidade ou abuso de poder.

A instituição do Conselho Nacional de Justiça não constitui novidade no direito brasileiro.

Com efeito, a Reforma Judiciária realizada em 1977, por meio da Emenda Constitucional $n^{\circ}$ 7, de abril de 1977, criou o Conselho Nacional da Magistratura, composto de sete ministros do Supremo Tribunal Federal.

Na ocasião, o legislador constituinte atendeu à sugestão formulada pela Comissão Especial do Supremo Tribunal Federal, integrada pelos Ministros Thompson Flores, Rodrigues Alckmin e Xavier de Albuquerque, encarregada de elaborar o célebre "Diagnóstico do Poder Judiciário", o mais completo estudo até hoje realizado acerca do Poder Judiciário ${ }^{5}$ FREITAS, Vladimir P. de. Conselho Nacional de Justiça. Jornal Gazeta do Povo, 18 jan. 2005. 
no Brasil.

Nesse histórico documento, constava, verbis:

29. Ponto de capital importância diz com a disciplina do Poder Judiciário. Assegurada condigna situação aos magistrados, é indispensável que a correspondente responsabilidade pelo bom desempenho das funções do cargo possa ser efetivamente estabelecida. Assim, sem prejuízo ou absorção das atividades fiscalizadoras ou repressivas dos órgãos competentes das Justiças Federais e das Justiças dos Estados, é mister órgão superior ou Conselho Judiciário Nacional, a quem caiba intervir, dentro de determinados limites, para a supressão de irregularidades mais graves, não somente quanto à atividade dos Juízes, mas também dos mais órgãos ou instituições ligadas ao Poder Judiciário. Tal órgão, estruturado dentro do Supremo Tribunal Federal para manter a independência dos Poderes, exerceria ampla função censória, para prover prontamente quando mister. ${ }^{6}$

\section{Em precioso estudo, registrou o Professor Alcino Salazar, verbis:}

Ponto fundamental da reforma a ser empreendida, já ressaltado, é o da instituição de um órgão de cúpula com atribuições de ordem administrativa e poder disciplinar dominante. Sua finalidade essencial será, a um tempo, a de exercer a supervisão do funcionamento de todos os órgãos, titulares e agentes da área do Poder Judiciário de sorte a preservar sua unidade orgânica e a de exercer o pleno comando hierárquico quanto aos deveres e responsabilidades funcionais de todos.

A disciplina da magistratura, padronizada e efetiva, em todas as suas graduações, é elemento assegurador, por excelência, da boa administração da justiça, do proveitoso rendimento de sua atividade.

O exercício do poder hierárquico é, antes de tudo, decorrência da sua condição de um dos três Poderes da República, com independência assegurada na Constituição.

Não se justifica, nem se compreende, a posição de isolamento e de funcionamento autônomo dos diferentes órgãos do Poder Judiciário, quer os das Justiças especializadas, quer os da Justiça comum, federal ou estadual, vivendo cada um sua existência, sem qualquer laço de subordinação hierárquica de caráter administrativo.

Pode-se dizer que os diferentes órgãos da Justiça brasileira formam um arquipélago, cujas ilhas estão cercadas de autonomia por todos os lados....

Os diferentes tribunais não se ligam ao órgão supremo nem por laços de subordinação, nem mesmo de coordenação, relativamente a suas atribuições de ordem administrativa. Elaboram independentemente os seus regimentos e assim organizam e administram os seus serviços. Os relatórios anuais de seus trabalhos são dirigidos apenas aos seus titulares. Seus problemas de instalação, aparelhamento material, administração de pessoal e instrumentos de realização

${ }_{6}^{6}$ Reforma do Poder Judiciário - Diagnóstico. Supremo Tribunal Federal. Brasília, 1975, p. 30-31. 
dos vários serviços correm igualmente à revelia do órgão de cúpula. São solucionados segundo critérios diferenciados ou deixados sem solução.

A este respeito, os mencionados relatórios, principalmente dos Estados (o que foi possível obter como elementos de informação para o presente livro) têm tido manifestações expressivas quanto ao estado ruinoso até dos edifícios sedes dos serviços da Justiça nas capitais estaduais.

Cada tribunal ostenta, não raro, com sua independência em relação ao Poder que integra, as suas privações e dificuldades, estas, ao contrário, na dependência de outros Poderes, que ou não as consideram, ou não dispõem de meios para supri-las ou removê-las.

Por outro lado, o Tribunal máximo não interfere em tais problemas. Deles não tem cogitado. Os relatórios anuais de seus trabalhos limitam suas considerações às deficiências e dificuldades do próprio Tribunal. ${ }^{7}$

Quando da instalação do Conselho Nacional da Magistratura, em 21.05.1979, disse o então Presidente do Supremo Tribunal Federal, o Ministro Antonio Neder, verbis:

As influências na judicatura e as fraquezas inerentes à qualidade humana do magistrado são dois aspectos do mal gravíssimo que, embora raro, ofende a Justiça.

Para remediar as primeiras, a Constituição confere ao julgador algumas garantias: vitaliciedade, inamovibilidade, irredutibilidade dos vencimentos.

Esses direitos permitem que o juiz resista a qualquer influência, ainda que provenha de poderosos e governantes.

Colocam-no ao abrigo da lei, exclusivamente da lei, a cujo império deve submeter-se.

Contudo, no que diz respeito às fraquezas humanas, tais garantias constitucionais não produzem resultado corregedor.

É que, inerentes ao homem que subjaz no magistrado, as imperfeições convivem obviamente com ele e podem influenciá-lo ao ensejo do julgamento.

Com ressalva do processo disciplinar, nenhum outro remédio jurídico existe para obviar aos desacertos próprios do homem que vive no juiz.

Dito processo foi adotado pelos países de rica vivência judiciária e profunda experiência no campo do Direito Público: França e Itália.

Seus Juristas conceberam a instituição e um órgão judiciário de alta hierarquia para disciplinar o comportamento dos magistrados.

Fizeram-no para o fim de conduzir o juiz a sobrepor-se ao homem que o envolve, isto é, às fraquezas humanas que possam dominá-lo; para o fim de o julgador transformar-se, no processo, em serena voz do direito, exclusivamente dele; para o fim de, na sentença, perseguir a finalidade construtiva da regra

7 SALAZAR, Alcino. Poder Judiciário - Bases para Reorganização. Rio de Janeiro: Forense, 1975, p. 245-246. 
jurídica, tal como deve fazer o sacerdote que transmite a mensagem religiosa; para o fim de impedir que as mencionadas garantias constitucionais produzam resultado aberrante, amparando o juiz, que deslustra a Justiça.

Fizeram-no também para impor ao Juiz que se comporte dentro da normalidade que lhe é indicada pela regra moral de conduta; normalidade no conduzir-se com a postura serena e humilde, autêntica expressão de austeridade sem requinte nem capricho, aquela que o faz respeitado por todos; normalidade no trato com as pessoas, no qual tempera seu irrenunciável direito de afeiçoar-se e cumpre seu imperioso dever de afastar, com elegância, o convívio íntimo de quase todas, inclusive, notadamente, o daquelas que lhe possam comprometer a consideração; normalidade no praticar seus atos, mostrando que não é homem capaz de apaixonar-se, a não ser pela santificante preocupação de vencer, com as armas próprias do seu ofício, a ousadia dos poderosos, o rancor dos inferiores, a crítica terrível e corrosiva dos vencidos ou condenados; normalidade no manter uma consciência minuciosamente afinada pela discreção, e, portanto, invariavelmente firmada pela vontade.

Para concretizar o moralizador objetivo de impedir que as deficiências humanas conspirem contra o magistrado, que tais deficiências possam conduzir o juiz a cometer abusos, idealizaram os juristas europeus, como foi lembrado acima, um órgão judiciário superior e disciplinar, para o julgamento do juiz que não haja cumprido a sua missão.

Esse órgão, no Brasil, é o Conselho Nacional da Magistratura, instituído pela Emenda Constitucional $n^{\circ} 7$ de 1977, que o colocou na cúpula do Poder Judiciário, integrado por Ministros do Supremo Tribunal Federal. ${ }^{8}$

O Conselho Nacional de Justiça, ora criado pela Emenda Constitucional $n^{\circ} 45 / 04$, possui atribuições mais amplas que o da Constituição anterior, sendo, todavia, diversa a sua composição.

Somente o passar do tempo poderá atestar a sabedoria e a eficácia das inovações implementadas pela recente reforma judiciária. Eventuais desacertos serão, naturalmente, emendados.

Impende, contudo, acentuar que ao Conselho Nacional de Justiça descabe o exame de decisões jurisdicionais proferidas pelos juízes. Nesse sentido, foi acertada a opção do constituinte, pois, caso contrário, estarse-ia violando a garantia da independência dos magistrados.

Cabe, aqui, recordar as sábias palavras de Franqueville, verbis: "Il ne suffit pas que les juges soient inamovibles pour être indépendants; il faut encore qu'ils ne se trouvent mêlés, en aucune façon, au gouvernement et, par suite, aux luttes des partis". ${ }^{9}$

E mais, comprometeria a própria tripartição dos poderes do Estado,

${ }^{8}$ STF. Relatório - 1980. Brasília, p. 84-85. 
insculpida no art. $2^{\circ}$ da Lei Maior, que segundo Burdeau foi "la règle d'or de la démocratie gouvernée".

É oportuno transcrever o seu magistério, verbis: "Et c'est bien pourquoi, protection contre l'arbitraire du monarque autant que contre la tyrannie des majorités, la séparation des pouvoirs a été la règle d'or de la démocratie gouvernée. Après avoir servi à ruiner l'absolutisme monarchique, elle fut utilisée pour contenir la souveraineté populaire". ${ }^{10}$

\section{4 Órgãos congêneres do Direito comparado}

Terminada a Segunda Guerra Mundial, a França e a Itália instituíram em suas respectivas Constituições um Conselho Superior da Magistratura visando garantir a independência dos juízes, subtraindo a magistratura da tutela do Poder político.

Nesse sentido, registra Thierry Ricard, verbis: "Lémergence du Conseil supérieur de la magistrature dans l'histoire de l'organisation judiciaire apparaît, en effet, comme la réponse républicaine au souci de préserver la justice des influences de la puissance exécutrice de l'Etat". ${ }^{11}$

Embora bem intencionada, a idéia da criação do Conselho Superior da Magistratura, acolhida pela Carta de 1946, fracassou em seus objetivos, consoante noticia o Ministro da Justiça do Presidente De Gaulle, Michel Debré, em suas conhecidas memórias, verbis:

Les constituants de 1946 ont senti qu'il y avait un problème. Ils créèrent un Conseil Supérieur de la Magistrature pour veiller à la carrière des juges. L'idée était bonne; la réalisation fut médiocre: une part des magistrats était élue par les diverses catégories de juges et une autre par l'Assemblée nationale en fonction d'accords entre formations dominantes. Ce mélange de corporatisme et de partisanerie politique ne pouvait en rien relever la justice, au point qu'il existe en 1958 un accord général sinon sur la solution, en tout cas sur le principe d'une réforme. ${ }^{12}$

O Conselho Superior da Magistratura na França possui atribuições administrativas e disciplinares.

Na Itália, o Conselho Superior da Magistratura encontra-se previsto no art. 105 da Constituição de 1947 o qual compete, tal qual o similar

\footnotetext{
9 FRANQUEVILLE, Le Cte De. Le Système Judiciaire de la Grande Bretagne - Organisation Judiciaire. Paris: J. Rothschild Éditeur, 1893, t. 1, p. 386, n. IV.

10 BURDEAU, Georges. Traité de Science Politique. 2. ed. Paris: L. G. D. J., 1971, t. VI, v. 2, p. 408.

${ }^{11}$ RICARD, Thierry. Le Conseil Supérieur de La Magistrature. Paris: PUF, 1990, p. 3. Nesse sentido, também,

a obra coletiva organizada por RENOUX, Thierry S. Les Conseils Supérieurs de La Magistrature en Europe.

Paris: La Documentation Française, 1999, p. 9 et seq.

12 DEBRÉ, Michel. Trois Républiques pour une France - Mémoires. Paris: Albin Michel, 1988, v. II, p. 334.
} 
francês, atribuições de natureza administrativa e disciplinar.

No que concerne à sua composição e competência, informam Carlo

Guarnieri e Patrizia Pederzoli, verbis;

L'Italia è senza dubbio il paese cha ha conosciuto sotto questo profilo le trasformazioni di più ampia portata e probabilmente anche il solo ad aver realizzato, nel senso proprio del termine, il principio di autogestione della magistratura. Dopo l'esperienza autoritaria del ventennio fascista, la Costituzione ha infatti reciso la maggior parte dei canali istituzionali tra il giudiziario e gli altri poteri, in particulare l'esecutivo. Tutte le decisioni che ineriscono allo status sia dei giudice sia dei pubblici ministeri - reclutamento, promozioni, provvedimenti disciplinari, ecc. — sono state concentrate nella mani del Consiglio, che è così diventato il più importante canale di collegamento istituzionale tra la magistratura e il sistema politico. (...) Attualmente è formato da 3 componenti di diritto — il Capo dello stato, che lo presiede, il Primo presidente e il Procuratore generale della Corte di cassazione - 20 magistrati direttamente eletti da tutti i colleghi e 10 esperti in materie giuridiche, avvocati o docenti universitari, eletti dalle due camere del parlamento in seduta comune. Quanto alla designazione di questi ultimi, regola non scritta ma di fatto operante sino ad ora è stata quella di rispettare le proporzioni esistenti fra i principali gruppi parlamentari, ivi inclusa l'opposizione. ${ }^{13}$

Na América Latina, vêm sendo criados órgãos parecidos aos do direito europeu.

No caso da Argentina, sustenta Adrián Ventura o fracasso da instituição do "Consejo de la Magistratura", fruto da reforma constitucional de 1994, em razão do caráter predominantemente político de sua composição.

Eis o seu depoimento, verbis:

Paradójicamente, la reforma de 1994, que declamó la necesidad de independizar a la Justicia de tales influencias, terminó por entregar las atribuciones - en materia disciplinaria, administrativa y financiera - que antes eran de competencia exclusiva de la Corte Suprema a un órgano integrado por políticos. Se puede compartir la solución o sostener que, al contrario, la medicina terminará por matar al enfermo, pero lo cierto es que la finalidad del convencional reformador - por lo menos, el objetivo que explicitó - fue el de brindar a la Justicia la posibilidad de ser más independiente.

Evidentemente, no cabe pretender que se cumpla ese fin si el Consejo tiene un perfil eminentemente político, pues las pasiones que despierta el ejercicio del poder terminarán por doblegar a la judicatura. ${ }^{14}$

\section{Considerações finais}

A Reforma Judiciária promovida pela Emenda Constitucional $\mathrm{n}^{\mathrm{o}}$

${ }^{13}$ GUARNIERI, Carlo. La Democrazia Giudiziaria. Bologna: Società Editrice il Mulino, 1997, p. 45/7.

A \& C R. de Dir. Administrativo e Constitucional, Belo Horizonte, ano 6, n. 23, p. 21-37, jan./mar. 2006 
45/04 pouco fez para resolver o verdadeiro problema do Poder Judiciário, que é a demora na prestação jurisdicional.

Lamentavelmente, dita reforma iniciou-se sem a indispensável elaboração, por parte dos órgãos competentes, sobretudo o Supremo Tribunal Federal, dos necessários estudos preliminares, com a feitura de um verdadeiro "Diagnóstico da Justiça", após a colheita dos dados imprescindíveis à confecção desse importante documento.

Nesse sentido, colha-se a advertência do notável magistrado Arthur T. Vanderbilt, em sua clássica obra Minimum Standards of Judicial Administration, verbis: "Most judicial reforms fail, or are disappointing, because they are not based on adequate study of the particular conditions in which they are expected to operate or because they are adopted without adequate comparison with the experience with similar attempts, of finally because they lack the support of the moral force of the community". ${ }^{15}$

Ademais, outras providências objetivas precisam ser adotadas no âmbito da União com o propósito de descongestionar a Justiça, sobretudo a tão reclamada simplificação das leis processuais, conferindo-se efetividade às decisões judiciais para que sejam cumpridas sem delongas, em especial aquelas que envolvam o Poder Público.

Em exaustivo estudo encomendado pelo Ministério da Justiça da França, conclui, nesse tópico, o Magistrado Jean-Marie Coulon, verbis: "L'effectivité des decisions de justice est la condition du respect de l'autorité judiciaire et de la sécurité juridique. Une bonne et promte exécution des jugements (qui représentent $86 \%$ des décisions judiciaires) constitue le fondement de la crédibilité de la justice". ${ }^{16}$

O aumento da litigiosidade na esfera cível envolvendo o Poder Público tende a aumentar, motivo pelo qual precisam ser adotadas, com urgência, medidas legislativas que permitam às pessoas lesadas em seu direito a pronta execução do julgado, agora com mais razão considerandose o disposto no art. $5^{\circ}$, LXXVIII, da CF/88, na redação da Emenda Constitucional $n^{\circ} 45 / 04$.

No final dos anos sessenta, tal fenômeno já era detectado nos

\footnotetext{
4 VENTURA, Adrián. Consejo de la Magistratura. Buenos Aires: Depalma, 1988, p. 202-203.

15 VANDERBILT, Arthur T. Minimum Standards of Judicial Administration. New York: The Law Center of New York University, 1949, p. 65.

${ }^{16}$ COULON, Jean-Marie. Réflexions et Propositions sur la Procédure Civile. Paris: La Documentation Française, 1997, p. 106. Nesse sentido, também, a obra coletiva PERROT, Roger (Org.). La Réforme des Procédures Civiles d'exécution. Paris: Sirey, 1993, p. 166-167.
} 
Estados Unidos, ocasionando o congestionamento das Cortes Federais de Apelação.

É o que informa Paul D. Carrington, Professor da Michigan Law School, em artigo publicado na prestigiada Harvard Law Review, verbis:

It seems quite likely that the United States will become involved in more civil disputes in the future. This prognosis rests not merely on a prediction that the Government will be involved in more and larger programs involving a larger number of potential adversaries, but also on a prediction about the attitude of those potential litigants toward litigation.

A modern trend has favored subsidy over regulation for new programs. To an increasing degree, such programs are regarded less as acts of grace by a benevolent government, and more as a source of proprietary rights that are suitable subjects of litigation, and it seems not unlikely that challenges will receive a hospitable hearing in the federal courts. ${ }^{17}$

Por outro lado, impõe-se, também, o aprimoramento do sistema de recrutamento de juízes.

Nesse passo, papel relevante poderá ser desempenhado pelo Conselho Nacional de Justiça, podendo o futuro Estatuto da Magistratura criar junto a esse órgão um Centro Nacional de Estudos Judiciários que forneceria propostas de aperfeiçoamento do modelo de ingresso na magistratura.

Esse importante aspecto da reforma judiciária já havia sido tratado no Diagnóstico da Justiça elaborado pelo Supremo Tribunal Federal, em 1975, verbis:

27. A primeira e capital dificuldade está no recrutamento de bons Juízes. É dizer o óbvio afirmar que, sem magistrados de excelente formação moral e intelectual, não haverá Poder Judiciário altamente capaz.

O recrutamento de juízes, no primeiro grau, se faz por meio de concursos. Há mister, porém, que a seleção, para ser profícua, se realize entre o maior número possível de candidatos. E que se adotem os melhores critérios.

Quanto ao primeiro aspecto, é preciso tornar mais atrativa a carreira, assegurando-lhe melhores ganhos e vantagens.

(..)

Quanto ao segundo aspecto - melhores critérios de recrutamento - a par da conveniência do concurso de ingresso em duas fases, permitindo que entre elas se insira estágio probatório, mencione-se a idéia da criação de cursos ou institutos

\footnotetext{
17 CARRINGTON, Paul D. Crowded Dockets and The Courts of Appeals: The Threat to the Function of Review and the National Law. Harvard Law Review, v. 82, p. 548/9,1968/9.
} 
de preparação para a magistratura, semelhantes ao Centre National d'Etudes Judiciaires, com desejável intercâmbio entre Universidades e Tribunais, para a seleção dos melhores alunos. ${ }^{18}$

A preocupação quanto ao tema, como se vê, vem de longe.

A questão foi abordada, e com profundidade, pelo $1^{\circ}$ Congresso Internacional de Magistrados, realizado em Roma, de 11 a 13 de outubro de 1958, consoante consta das conclusões desse histórico e prestigiado evento, verbis:

1) Auspica che, per la preparazione alla funzione giudiziaria, il futuro Magistrato possa trovare nelle università l'insegnamento delle discipline moderne indispensabili all'esercizio della funzione giudiziaria.

2) Auspica che, tenuto conto della particolarità delle funzioni giudiziarie e della preparazione necessaria a chi le esercita, siano istituiti in relazione e secondo l'indole giuridica di ogni ordinamento giudiziario, centri di preparazione, ricerca e studio, i quali procedano, con unità di metodo, alla formazione del Magistrato.

Conseguentemente l'avere partecipato ai corsi relativi deve, in via de massima, costituire una condizione essenziale per essere nominato o designato od eletto ad una funzione giudiziaria, o, comunque, per essere immesso nell'effettivo esercizio della funzione.

3) Laddestramento del Magistrato deve tendere: ad integrare le nozioni extra giuridiche necessarie allo svolgimento delle funzioni giudiziarie (studi di economia, sociologia, psicologia e criminologia); alla discussione e valutazione del caso concreto; alla diretta partecipazione all'attività dei centri di osservazione presso gli Istituti di Prevenzione e di Pena. Questo addestramento deve costituire una fase sperimentale ed applicativa, in cui chi conduce la ricerca, in unione di lavoro con l'allievo, solleciti l'autoformazione di quest'ultimo.

Sembra opportuno che ad una prima fase de studio teorico ed applicativo segua un periodo di pratica professionale, a cui potrà seguire una prova finale $\mathrm{o}$, comunque, una valutazione o classificazione dei singoli candidati. ${ }^{19}$

Portanto, há muito ainda a ser feito.

Frise-se, no entanto, que o momento é propício para a realização dos estudos necessários e a execução da ambicionada reforma.

Importa restabelecer-se o espírito da reforma - a expressão é do ilustre Ministro Xavier de Albuquerque -, sob pena de perdermos uma histórica oportunidade de empreender o aperfeiçoamento das instituições judiciárias, objetivo incessantemente buscado pelas últimas Constituições brasileiras, sobretudo a partir de 1946.

\footnotetext{
18 Op. cit., p. 28/30. Na França, consulte-se a obra de CHAZELLE, René. Pour Une Reforme Des Institutions Judiciaires. Paris: L.G.D.J., 1969, p. 66/71.

19 Primo Congresso Internazionale dei Magistrati. Milano: Dott. A. Giuffrè Editore, 1959, t. II, p. 1.207.
} 
A propósito, não se perca de vista o célebre aforisma do Cardeal de Retz, verbis: "Nada existe no mundo que não tenha seu momento decisivo e a obra prima do procedimento avisado é reconhecer e escolher esse momento". ${ }^{20}$

Este é o momento e confio que da conjugação desse esforço poderá nascer um Judiciário forte e atuante, distribuindo a melhor Justiça, assim qualificada pelo saudoso Ministro Thompson Flores em seu discurso de posse na Presidência do Supremo Tribunal Federal, verbis:

Justiça que brote de juízes independentes, sem falsos ou mal compreendidos exageros, como sempre o foram os juízes do Rio Grande, reconhecidos urbe et orbe, sem cujo atributo nem é possível conceber o exercício funcional como ele se impõe.

Justiça austera, impoluta, incorruptível, como se faz mister o seja e para cujos imperativos prosseguiremos indormitos e intransigentes.

Justiça humana como merece distribuída às criaturas feitas à imagem de Deus.

Justiça que jamais se aparte dos fins sociais e das exigências do bem comum, sem cuja presença nem seria compreendida.

Justiça que se aproxime, sem excessos ou enganosas fórmulas, do próprio povo para a qual é ditada e do qual deve estar sempre ao alcance; simples, real, despida de tudo que a possa tornar dificultosa, a fim de que a compreenda melhor, sinta-a com fervor, e possa, assim, nela crer para amá-la, prestigiá-la, e defendê-la se preciso for, convencido que ela é seu baluarte democrático e a sua mais sólida garantia.

Justiça da qual se não permita desconfiar um só segundo, porque como assinalava Balzac: "Desconfiar da Magistratura é um começo de dissolução social".

E sobretudo Justiça pontual, como a queria Rui, porque tarda não mereceria o nobre título. E como dizia, reclamando: "Para que paire mais alto que a coroa dos reis e seja tão pura como a coroa dos santos".

Só assim nos tornaremos dignos do respeito e da confiança da Nação, ao lado dos demais Poderes da República. ${ }^{21}$

Somente assim o Poder Judiciário será respeitado pela Nação, juntamente com os Poderes Executivo e Legislativo.

Com a sua autoridade de principal redator da Constituição de 1958 e um dos fundadores da V República da França, afirma Michel Debré, verbis; "N'oublions jamais que la République a besoin d'une justice prestigieuse, c'est-à-dire d'une belle et forte magistrature". ${ }^{22}$

Senhores, devo desculpar-me de haver excedido o tempo que me

\footnotetext{
20 RETZ, Cardinal De. Mémoires. Paris: Classiques Garnier, 1998, p. 364.

21 STF. Relatório de 1977. Brasília: Departamento de Imprensa Nacional, p. 82-83.
} 
foi destinado.

Convencido que a reforma do Poder Judiciário, ampla e profunda, é não só necessária, como inadiável, confio que os Poderes da República, imbuídos de altos propósitos como a ocasião o exige, terão a capacidade e sobretudo a vontade política de conduzir os trabalhos da pretendida reforma, e medidas a ela complementares, notadamente no plano da legislação processual, até que ela se realize plenamente, como ansiamos nós os magistrados.

A Emenda Constitucional $n^{\circ} 45$ constitui um primeiro passo para os projetos que se seguirão, e dos quais merece destaque, pela sua relevância, o Estatuto da Magistratura, de iniciativa do Supremo Tribunal Federal.

Para concluir, recordo as palavras de um dos maiores juízes do Brasil em todos os tempos, o saudoso Ministro Orosimbo Nonato, verbis:

Fora inútil e baldio negar falhas e imperfeições no funcionamento do Poder Judiciário e que alguns de seus representantes delirem, acaso, das linhas rígidas do dever completo. A perfeição, como tantas vezes se lembra, desertou a terra depois que o anjo de espada fulmínea surgiu no ádito do paraíso perdido.

Toda instituição humana reflete o efêmero, o periturno, o imperfeito da humanidade.

Pena-me dizê-lo: juízes haverá, talvez, menos merecedores desse nome que, em verdade, por se manter lustroso e puro, exige atributos indeparáveis no comum dos homens, no ordinário das pessoas e, antes, constituem marcas dos seres de eleição.

Mas os juízes menos dignos constituem raras exceções, mercê de Deus exceções raríssimas na magistratura brasileira.

Em sua imensa maioria, e assoberbando, não raro, a inópia de recursos, a incompreensão de alguns, o ressentimento injusto de muitos, a cegueira de paixões de outros, o desestímulo do meio adversando dificuldades sem conto, e pelejando, à arca partida, contra obstáculos, ao parecer, invencíveis, cumprem eles o seu dever, às vezes amargo como o fel intransitivo dos grandes sacrifícios.

(...)

Detentor de um poder formidável, mas imbele, o juiz sempre contraria uma pretensão e os que a suscitaram e o seu séquito o elegem vítima piacular de recriminações, às vezes excessivas em sua acidez e desenvoltura e tão acesas de ódio que valem como perigosas sucessões da paz pública e por acenos ao tumulto e à aversão. ${ }^{23}$

Senhor Presidente.

22 Op. cit., p. 343.

A \& C R. de Dir. Administrativo e Constitucional, Belo Horizonte, ano 6, n. 23, p. 21-37, jan./mar. 2006 
Ao finalizar, renovo o meu reconhecimento pelas palavras proferidas por Vossa Excelência e pela presença de quantos vieram a este Plenário prestigiar o evento.

Muito obrigado.

Informação bibliográfica deste texto, conforme a NBR 6023:2002 da Associação Brasileira de Normas Técnicas (ABNT)

LENZ, Carlos Eduardo Thompson Flores. O Conselho Nacional de Justiça e a administração do Poder Judiciário. A\&C Revista de Direito Administrativo e Constitucional, Belo Horizonte, ano 6, n. 23, p. 21-37, jan./mar. 2006.

${ }^{23}$ Op. cit., p. $16 / 7$.

A \& C R. de Dir. Administrativo e Constitucional, Belo Horizonte, ano 6, n. 23, p. 21-37, jan./mar. 2006 